\title{
Change in Complete Blood Count Parameters and Vital Signs After Intravenous Infusion of 1 Liter of Normal Saline
}

\author{
Emre Gokcen ${ }^{1}$ (D), Yunsur Cevik ${ }^{(\mathbb{D})}$, Gul Pamukcu Gunaydin² (D), Nurettin Ozgur Dogan³ (D), Mustafa Tekin ${ }^{1}$ (D) \\ 'Department of Emergency Medicine, Kecioren Training and Research Hospital, Ankara, Turkey \\ 2Department of Emergency Medicine, Ankara Ataturk Training and Research Hospital, Ankara, Turkey \\ ${ }^{3}$ Department of Emergency Medicine, Kocaeli University School of Medicine, Kocaeli, Turkey
}

Cite this article as: Gokcen E, Cevik Y, Pamukcu Gunaydin G, Dogan NO, Tekin M. Changes in Complete Blood Count Parameters and Vital Signs After Intravenous Infusion of 1 Liter of Normal Saline. Eurasian J Emerg Med. 2018; 17: 71-4.

\begin{abstract} parameters and vital signs were recorded before and after administration of saline. in vital signs and complete blood count parameters due to hemodilution.

Keywords: Complete blood count, saline solution, vital signs

\section{Introduction}

Continuous cardiac monitoring, pulse oximetry, end-tidal carbon dioxide monitoring, arterial blood pressure, mental status, peripheral perfusion urine output, central venous pressure (CVP) measurements, a bedside ultrasound can be used in the follow-up of the fluid status of bleeding patients in the emergency department (1). In addition, hemoglobin $(\mathrm{Hb})$ and hematocrit $(\mathrm{Hct})$ values are also used to plan treatment for these patients (2).
\end{abstract}

Aim: In patients with suspected acute hemorrhage in the emergency department, the first-line of treatment is intravenous fluid therapy. The most frequently used parameters to estimate the amount of hemorrhage and to plan the management are the vital signs, hemoglobin $(\mathrm{Hb})$, and hematocrit $(\mathrm{Hct})$ values. In this study, we aimed to define possible changes in the vital signs, $\mathrm{Hb}$, and Hct values after intravenous infusion of $1 \mathrm{~L}$ normal saline in non-hemorrhagic patients to interpret the $\mathrm{Hb}$ and $\mathrm{Hct}$ values in hemorrhagic patients who receive the same treatment.

Materials and Methods: One hundred patients who presented to the emergency department of a training and research hospital between December 1 and 31,2012 , were included in the study. One liter of normal saline was given to patients who consented to participate in the study. The complete blood count

Results: Statistically significant decreases in pulse, systolic blood pressure, white blood cell count, $\mathrm{Hb}$, and Hct values were observed after the administration of saline $(p<0.001)$. The median $\mathrm{Hb}$ and $\mathrm{Hct}$ values decreased from 14.2 to $13 \mathrm{~g} / \mathrm{dL}(\mathrm{p}<0.001)$ and from $42.4 \%$ to $38.3 \%$ ( $p<0.001)$, respectively.

Conclusion: In the follow-up of patients who are given intravenous fluids, emergency department physicians should consider that some changes may occur

In patients with bleeding, Hct levels may decrease due to both blood loss and hemodilution caused by fluids that are given for initial resuscitation. Along with the decrease in Hct levels, changes occur in the number of red blood cells, $\mathrm{Hb}$, protein, and electrolyte levels in blood plasma. Another reason for the decrease in Hct levels is translocation of the liquid in the intracellular and interstitial area to the intravascular area to compensate the reduced intravascular volume caused by hemorrhage (3).

Currently, isotonic crystalloid solutions such as normal saline (NS) and Ringer's lactate(RL) are preferred solutions for fluid resuscitation in the emergency department because colloids are more expensive than crystalloids, and no better survival rates have been reported with colloids (4).

ORCID IDs of the authors: E.G. 0000-0002-6018-6105; Y.C. 0000-0003-1325-0909; G.P.G. 0000-0001-8531-4591; N.O.D. 0000-0002-52098076; M.T. 0000-0002-9310-708X.

Corresponding Author: Gul Pamukcu Gunaydin e-mail: gulpamukcu@yahoo.com 
Although NS infusion is one of the most frequently used treatments in the emergency department, the studies evaluating the decrease in $\mathrm{Hb}$ levels caused by NS infusion are conducted with small numbers of patients in medical literature. In this regard, further studies including larger numbers of patients are required (5-9).

In this study, our objective is to measure the effect of $1 \mathrm{~L} \mathrm{NS}$ infusion on complete blood count ( $\mathrm{CBC}$ ) parameters and vital signs of healthy individuals, and to use the differences to interpret changes in hemorrhagic patients who also receive NS treatment.

\section{Materials and Methods}

This study was conducted as a prospective observational clinical study in the emergency department of a training and research hospital. The annual number of patients seen in this department is approximately 200,000. The institutional ethical board approved the study protocol. All patients admitted to emergency department for December 2012 were evaluated in terms of inclusion and exclusion criteria, and appropriate patients were included after informed consent was obtained.

Inclusion criteria:

- $\quad$ Age $\geq 18$ years (there was no upper age limit);

- Presented to emergency department for reasons other than acute blood or fluid loss;

- Normovolemic in clinical evaluation at the time of admission.

Exclusion criteria:

- Age $<18$ years;

- Pregnant or breast-feeding;

- Hypovolemic or hypervolemic (congestive heart failure, cirrhosis, patients on dialysis, etc.) in clinical evaluation and physical exam;

- $\quad$ Presented to the emergency department for a condition causing acute blood loss (gastrointestinal hemorrhage, trauma) or fluid loss (diarrhea, emesis, ileus, burns, heat stroke, dehydration, etc.);

- Use of drugs acting on heart rate or blood pressure (calcium channel-blockers, beta-blockers, digitalis-digoxin, alcohol, illicit drugs, etc.);

- Previously diagnosed with anemia (The World Health Organization criterion for anemia in adults is a $\mathrm{Hb}$ value of less than $12.5 \mathrm{~g} / \mathrm{dL})$;

- Diagnosed with any myeloproliferative disease or cancer; and

- $\quad$ Patients with a Glasgow Coma Score $<15$.

Age and gender of the patients included in the study were recorded in a study form. Vital signs (body temperature, heart rate, peripheral capillary oxygen saturation $\left(\mathrm{SpO}_{2}\right)$, blood pressure, and respiration rate), height, and body weight of the patients were measured twice; 1 minute apart by different nurses working in the emergency department, and the mean was recorded on the study forms. Body temperature was measured using a tympanic body thermometer (Covidien Genius, MN, USA). Heart rate was measured as radial pulse for $15 \mathrm{~s}$ and multiplied by $4 . \mathrm{SpO}_{2}$ and blood pressure were measured using pulseoxymeter (Mindray PM 9000, Shenzen, China). The respiration rate was calculated for $30 \mathrm{~s}$ by inspection, and the number was multiplied by 2 . Height and weight were measured using a medical mechanical scale (NAN IB150, Istanbul, Turkey). Body mass index (BMI) was calculated using the formula body weight/ body height2.

A peripheral intravenous (IV) line was obtained using an $18 \mathrm{G}$ green branule in the antecubital region and $3 \mathrm{~mL}$ of blood was collected for $\mathrm{CBC}$. After blood samples were collected, the volunteers were given $1000 \mathrm{~mL}$ of NS (at room temperature) within 60 minutes through this IV line. Ten minutes after the NS infusion was completed, the vital signs were measured in a sitting position twice, 1 minute apart by different nurses, and mean of measurements was recorded in the study forms. Subsequently, $3 \mathrm{~mL}$ 's of blood samples were collected in purple-capped ethylene diamine tetra-acetic acid (EDTA) tubes for CBC measurement. These after treatment blood samples were collected from the opposite arm that was not used for IV line and saline infusion.

The blood samples were deposited in the laboratory within 10 minutes of collection. Each sample was analysed thrice in Sysmex XP-300 (Roche Diagnostics), and the arithmetic mean of these three measurements was calculated and used in following statistical analysis. During the 1-month period that the study was conducted internal and external quality controls of the biochemistry laboratory of the Training and Research Hospital revealed no errors.

\section{Statistical analysis}

The Statistical Package for Social Sciences (SPSS Inc.; Chicago, IL, USA) 11.0 software was used for data analysis. The Kolmogorov-Smirnov test was used to analyze for normality of the distribution of the data. Paired sample t-test was used for the analysis of dependent variables that were normally distributed (White Blood Cell [WBC] and Hct). The Wilcoxon test was used for the analysis of dependent variables not normally distributed (heart rate, $\mathrm{SpO}_{2}$, body temperature, respiratory rate, systolic blood pressure, diastolic blood pressure, $\mathrm{Hb}$, mean corpuscular volume [MCV], mean corpuscular $\mathrm{Hb}[\mathrm{MCH}]$, and mean corpuscular $\mathrm{Hb}$ concentration [MCHC]). The Mann-Whitney $\mathrm{U}$ test was applied to compare median values of delta $\mathrm{Hb}(\mathrm{Hb}$ before $\mathrm{NS}-\mathrm{Hb}$ after NS) and Hct (before and after NS) between genders and between obese and non-obese patients. Data were expressed as median and interquartile ranges. The mean difference values were expressed in $95 \%$ confidence intervals. A value of $p<0.05$ was considered statistically significant.

\section{Results}

A total of 100 volunteers were included in the study; 45 were men and 55 were women. The patients included in the study had clinical diagnoses of vertigo (23\%), upper respiratory tract infections (13\%), urinary tract infections or urinary stone disease (12\%), abdominal pain without a surgical cause (40\%), and others (12\%).

The mean age of patients was $27.7 \pm 12.2$ years. The median BMI of patients was 24.2 (range, 20.8-26.5).

After infusion of $1000 \mathrm{~mL}$ of NS, a decrease with statistical significance, was observed in the pulse rate and systolic blood pressure of the patients. The body temperatures, $\mathrm{SpO}_{2}$, respiratory rates, and diastolic blood pressures of the patients did not change significantly after infusion of $1000 \mathrm{~mL}$ of NS (Table 1). 
Table 1. Vital signs of the patients before and after infusion of $1000 \mathrm{~mL}$ NS

\begin{tabular}{|l|c|c|c|c|}
\hline & $\begin{array}{c}\text { First measurement } \\
\text { Median (IQR) }\end{array}$ & $\begin{array}{c}\text { Second measurement } \\
\text { Median (IQR) }\end{array}$ & p & Mean difference (95\% CI) \\
\hline Pulse (beats/min) & $90(80-100)$ & $85(80-90)$ & $<0.001$ & $6.07[3.61-8.53]$ \\
\hline $\mathrm{SpO}_{2}(\%)$ & $96(95-98)$ & $97(95-99)$ & 0.059 & $-0.31[-0.65-0.03]$ \\
\hline Temperature $\left({ }^{\circ} \mathrm{C}\right)$ & $36.7(36.4-37.2)$ & $36.8(36.4-37.2)$ & 0.167 & $0.10[-0.02-0.23]$ \\
\hline Respiratory rate & $15(15-16)$ & $15(15-15)$ & 0.044 & $0.35[-0.06-0.76]$ \\
\hline Systolic blood pressure $(\mathrm{mmHg})$ & $115(109-126)$ & $110(100-120)$ & 0.001 & $6.2[2.9-9.5]$ \\
\hline Diastolic blood pressure $(\mathrm{mmHg})$ & $70(60-76)$ & $67(59-71)$ & 0.057 & $2.6[-0.06-5.24]$ \\
\hline
\end{tabular}

IQR: interquartile range; $C l$ : confidence interval; $S P O^{2}$, peripheral capillary oxygen saturations

Table 2. Changes in complete blood count parameters before and after infusion of $1000 \mathrm{~mL}$ normal saline

\begin{tabular}{|l|c|c|c|c|}
\hline & $\begin{array}{c}\text { First measurement } \\
\text { Median (IQR) }\end{array}$ & $\begin{array}{c}\text { Second measurement } \\
\text { Median (IQR) }\end{array}$ & p & Mean difference (95\% CI) \\
\hline $\mathrm{Hb}(\mathrm{g} / \mathrm{dL})$ & $14.2(13.2-15.5)$ & $13.0(11.9-14.5)$ & $<0.001$ & $1.11[1.01-1.22]$ \\
\hline $\mathrm{Hct}(\%)$ & $42.4(39.2-46.0)$ & $38.3(34.7-43.0)$ & $<0.001$ & $3.43[3.02-3.85]$ \\
\hline $\mathrm{WBC}(/ \mu \mathrm{L})$ & $10050(8000-12375)$ & $9800(7450-11400)$ & $<0.001$ & $0.70[0.32-1.09]$ \\
\hline $\mathrm{MCV}(\mathrm{fL})$ & $87.6(82.8-90.8)$ & $87.4(83.1-91.0)$ & 0.229 & $-0.08[-0.38-0.22]$ \\
\hline $\mathrm{MCH}(\mathrm{pg})$ & $29.5(28.1-30.6)$ & $29.7(28.0-30.9)$ & 0.035 & $-0.09[-0.20-0.02]$ \\
\hline $\mathrm{MCHC}(\mathrm{g} / \mathrm{dL})$ & $33.7(33.2-34.1)$ & $33.9(33.3-34.3)$ & 0.009 & $-0.01[-0.26-0.25]$ \\
\hline
\end{tabular}

IQR: interquartile range; Cl: confidence interval; Hb: hemoglobin; Hct: hematocrit; WBC: white blood cells; MCV: mean corpuscular volume; MCH: mean corpuscular; MCHC: mean corpuscular hemoglobin concentration

After $1000 \mathrm{~mL}$ NS infusion, significant decreases in $\mathrm{Hb}, \mathrm{Hct}$, and WBC levels were observed, whereas there were no significant changes in $\mathrm{MCV}, \mathrm{MCH}$, and $\mathrm{MCHC}$ levels (Table 2). Hb levels decreased in 98 (98\%) patients, whereas they remained unchanged in $2(2 \%)$ patients. Hct levels were decreased in 99 (99\%) patients, whereas it remained unchanged in one (1\%) patient.

Median $\mathrm{Hb}$ decrease (mean $\mathrm{Hb}$ before NS- and mean $\mathrm{Hb}$ after NS) was $1.10 \mathrm{~g} / \mathrm{dL}$ in males and $1.0 \mathrm{~g} / \mathrm{dL}$ in females, with no significant difference $(p=0.857)$. The median Hct (mean Hct before NS and mean Hct after NS) decrease was 2.80 in males and 3.2 in females, with no significant difference $(p=0.989)$.

When patients were divided into 2 groups according to BMI: 10 patients were obese $(\mathrm{BMI} \geq 30)$ and 90 were non-obese $(\mathrm{BMl}<30)$. Median $\mathrm{Hb}$ decrease was $1.10 \mathrm{~g} / \mathrm{dL}$ in non-obese and $1.0 \mathrm{~g} / \mathrm{dL}$ in obese patients, with no significant difference. $(p=0.549)$. Median Hct decrease was 3.10 in non-obese and 2.75 in obese patients. There was no significant difference $(p=0.625)$.

\section{Discussion}

In the emergency department, infusion of 1-2 liters of NS is recommended for adult patients who present with hemorrhagic shock (10). Hb levels and vital signs are used to detect hemorrhage and amount of bleeding in the follow-up of patients. In our study, the volunteer group included young adults. Our results show that even in the absence of hemorrhage, $\mathrm{Hb}$ and $\mathrm{Hct}$ values decrease due to NS infusion; thus, emergency physicians should cautiously interpret $\mathrm{Hb}$ or Hct decrease in those patients.
In medical literature, some studies conducted in small groups of patients found that $\mathrm{Hb}$ and Hct levels decreased after infusion of NS $(6,11,12)$. Lobo et al. (8) in their study infused $2000 \mathrm{~mL}$ of $5 \%$ dextrose or NS in two groups of patients, and they reported that $\mathrm{Hb}$ levels decreased significantly in 1 hour in both groups. Grathwohl et al. (7) in their study reported that $\mathrm{Hb}$ levels decreased by an average of $1.5 \mathrm{~g} / \mathrm{dL}$ and Hct levels decreased by an average of $4.1 \%$ within 1 hour after bolus infusion of $2000 \mathrm{~mL}$ of NS. In another study, it is reported that two-thirds of the isotonic fluid infused after blood loss left the vessels after a period (13). In our study, Hb levels of the patients decreased by an average of $1.11 \mathrm{~g} / \mathrm{dL}$ (range, 1.01-1.22), and $\mathrm{Hct}$ values decreased by an average of $3.43 \%$ (range, 3.02-3.85) in the follow-up after infusion of $1 \mathrm{~L}$ of NS, and the difference was statistically significant $(p<0.005)$.

Karaaslan et al. (9) reported that replacement with NS after of two units of blood was withdrawn from patients led to decrease in $\mathrm{Hb}$ and Hct levels, and they observed that NS infusion prevented heart rate changes initially after the replacement but could not prevent the decrease in mean arterial pressure. In our study, we observed that after infusion of $1000 \mathrm{~mL}$ of NS, systolic blood pressure and pulse rate of the patients decreased. In our study, patients with volume loss and hemorrhage were excluded; therefore, no hypotension and tachycardia were expected due to volume loss. Lobo et al. suggested that a sudden fluid load decreased the renin-aldosterone levels and led to the decrease of systolic blood pressure (8). Our study findings are consistent with that of Lobo et al. In literature, several studies report a rise in blood pressure after fluid resuscitation in hypotensive patients. Our results cannot be generalized to hypovolemic or 
hypotensive patients, because our study included only normotensive and normovolemic patients.

In literature, various studies with normovolemic subjects have shown that hydration with NS had no effect on the $\mathrm{SpO}_{2}$ (14). Our study also included normovolemic patients, and there were no significant changes in the $\mathrm{SpO}_{2}$ levels after the fluid therapy; our results were consistent with literature.

Although it has been shown in some studies that fluid therapy reduced the body temperature, there were no significant differences between pre-and post-hydration body temperatures in our study (15, 16). This may be due to the temperature of fluids given or the infusion speed. We have used NS that was stored at room temperature.

To our knowledge, there are no studies showing a direct relationship between NS therapy and respiratory rate in healthy patients. In our study, there was no significant change in respiratory rate after treatment with NS.

Moreover, there are no studies directly investigating the changes in WBC, MCV, MCH, and MCHC levels after NS therapy. In our study, we found that WBC, Hb, and Hct levels decreased, whereas MCV, MCH, and $\mathrm{MCHC}$ levels remained unchanged after fluid resuscitation.

\section{Study limitations}

Since the patients who use drugs that affect the heart rate and blood pressure were excluded, our study population is younger when compared to the general population who are admitted to the emergency department. We have not used any objective method of measurement other than history and physical examination and clinical judgment for the estimation of volume status of patients and that may be a source of bias. The vital sign measurements used in this study indirectly reflect volume status and may be influenced by multiple factors, such as experienced stress or pain on an emergency department visit. Only normovolemic patients were included so results may not be generalized to hypervolemic or hypovolemic patients.

\section{Conclusion}

In our study, $\mathrm{SpO}_{2}$, body temperature, respiratory rate, and diastolic blood pressure were not affected by hydration with $1 \mathrm{~L}$ of NS. Pulse rate and systolic blood pressure decreased after hydration. Regarding CBC parameters, WBC, $\mathrm{Hb}$, and Hct levels decreased, whereas MCV, $\mathrm{MCH}$, and $\mathrm{MCHC}$ remained unchanged after hydration with NS. These findings should be considered particularly when evaluating patients for whom $\mathrm{Hb}$ and $\mathrm{Hct}$ levels are measured frequently for follow-up and are administered fluids.

Ethics Committee Approval: Ethics committee approval was received for this study from the ethics committee of Kecioren Training and Research Hospital (Date: 28.11.2012/Number 155).

Informed Consent: Written informed consent was obtained from patients who participated in this study.

Peer-review: Externally peer-reviewed.

Author Contributions: Concept - E.G., Y.C., G.P.G., N.O.D., M.T.; Design - E.G., Y.C., G.P.G., N.O.D., M.T.; Supervision - E.G., Y.C., G.P.G., N.O.D., M.T.; Resources
- E.G., Y.C., G.P.G., N.O.D., M.T.; Materials - E.G., Y.C., G.P.G., N.O.D., M.T.; Data Collection and/or Processing - E.G., Y.C., G.P.G., N.O.D., M.T.; Analysis and/ or Interpretation - E.G., Y.C., G.P.G., N.O.D., M.T.; Literature Search - E.G., Y.C., G.P.G., N.O.D., M.T.; Writing Manuscript - E.G., Y.C., G.P.G., N.O.D., M.T.; Critical Review - E.G., Y.C., G.P.G., N.O.D., M.T.; Other - E.G., Y.C., G.P.G., N.O.D., M.T.

Conflict of Interest: The authors have no conflict of interest to declare.

Financial Disclosure: The authors declared that this study has received no financial support.

\section{References}

1. Cabanas JG, Manning JE, Cairns CB. Fluid and blood resuscitation. In: Judith ET, Stephan JS, John OM, David MC, Rita KC, Garth DM, editors. Tintinalli's Emergency Medicine. A Comprehensive Study Guide (7 th. ed.). New York: Mc Graw Hill Education; 2011.p.172-7.

2. Nijboer JM, van der Horst IC, Hendriks HG, ten Duis HJ, Nijsten MW. Myth or reality: hematocrit and hemoglobin differ in trauma. J Trauma. 2007; 62: 1310-2. [CrossRef]

3. Gutierrez G, Reines HD, Wulf-Gutierrez ME. Clinical review: hemorrhagic shock. Crit Care. 2004; 8: 373-81. [CrossRef]

4. Perel P, Roberts I, Ker K. Colloids versus crystalloids for fluid resuscitation in critically ill patients. Cochrane Database Syst Rev. 2013; 2: CD000567.

5. Guly HR, Bouamra O, Spiers M, Dark P, Coats T, Lecky FE. Trauma Audit and Research Network. Vital signs and estimated blood loss in patients with major trauma: testing the validity of the ATLS classification of hypovolaemic shock. Resuscitation. 2011; 82: 556-9. [CrossRef]

6. Lobo DN, Stanga Z, Aloysius MM, Wicks C, Nunes QM, Ingram KL, et al. Effect of volume with 1 liter intravenous infusions of $0.9 \%$ saline, $4 \%$ succinylated gelatine (Gelfusine) and 6\% hydrocyethyl starch (voluven) on blood volume and endocrine responses: a randomized, threeway crossover study in healthy volunteers. Crit Care Med. 2010; 38: 464-70. [CrossRef]

7. Grathwohl KW, Bruns BJ, LeBrun CJ, Ohno AK, Dillard TA, Cushner HM Does hemodilution exist? Effects of saline infusion on hematologic parameters in euvolemic subjects. South Med J. 1996; 89:51-5. [CrossRef]

8. Lobo DN, Stanga Z, Simpson JA, Anderson JA, Rowlands BJ, Allison SP. Dilution and redistribution effects of rapid 2-litre infusions of $0.9 \%(\mathrm{w} / \mathrm{v})$ saline and $5 \%(\mathrm{w} / \mathrm{v})$ dextrose on hematological parameters and serum biochemistryin normal subjects: a double-blind crossover study. Clin Sci (Lond). 2001; 101: 173-9. [CrossRef]

9. Karaaslan K, Durmufl M, But AK, Ersoy Ö, Arınç H. Akut Normovolemik Hemodilüsyonun Koroner Arter Bypass Cerrahisinde Etkileri. Türk Göğüs Kalp Damar Cer Derg. 2005; 13: 77-83.

10. Shock. In: Rotondo MF, editor. Advanced Trauma Life Support Student Course Manual. 9th edition, Chicago; 2012:72.

11. Stamler KD. Effect of crystalloid infusion on hematocrit in nonbleeding patients, with applications to clinical traumatology. Ann Emerg Med. 1989; 18: 747-9. [CrossRef]

12. de Aguilar-Nascimento JE, Valente AC, Oliveira SS, Hartmann A, Slhessarenko N. Changes in body composition, hematologic parameters, and serum biochemistry after rapid intravenous infusion or oral intake of 2 liters of $0.9 \%$ saline solution in young healthy volunteers: randomized crossover study. World J Surg. 2012; 36: 2776-81. [CrossRef]

13. Sell SL, Avila MA, Yu G, Vergara L, Prough DS, Grady JJ, et al. Hypertonic resuscitation improves neuronal and behavioral outcomes after traumatic brain injury plus hemorrhage. Anesthesiology. 2008; 108: 873-81. [CrossRef]

14. Chien JC, Jeng MJ, Soong WJ, Hwang B. Effects of fluid resuscitation on cerebral on cerebral tissue oxygenation changes in piglet model of hemorrhagic shock. J Chin Med Assoc. 2011; 74: 448-54. [CrossRef]

15. Mitchell KJ, Moncure KE, Onyeije C, Rao MS, Siram S. Evaluation of massive volume replacement in the penetrating trauma patient. J Natl Med Assoc. 1994; 86: 926-9.

16. Di Somma S, Gori CS, Grandi T, Risicato MG, Salvatori E. Fluid assessment and management in the emergency department. Contrib Nephrol. 2010; 164: 227-36. [CrossRef] 